Форет Ирина Валерьевна

кандидат исторических наук, доцент кафедры регионоведения и экономики зарубежных стран

Воронежского государственного университета

\section{ПРОБЛЕМЫ РЕАЛИЗАЦИИ ПРАВА БЕЖЕНЦЕВ НА ВОССОЕДИНЕНИЕ С СЕМЬЕЙ В ЕС}

Аннотация:

Миграционный кризис стал важным фактором политических процессов, регионализации и развития европейской интеграции. В статье анализируются проблемы реализации права беженцев на воссоединение с семьей в праве Европейского союза. Статья сфокусирована на актуальных проблемах миграции и противоречиях миграционной политики, с которыми сталкиваются современные страны - члены Европейского союза, включая право беженцев на воссоединение с семьей. Проанализированы проблемы статуса беженцев в контексте права на воссоединение семей, и показано, что общеевропейская позиция права в этом вопросе игнорируется некоторыми членами Европейского союза. При этом рост числа беженцев стимулировал страны ЕС использовать ограничительные меры, включая право на воссоединение семей. Автор предполагает возможность нескольких вариантов развития событий («либеральный», «консервативный», «выборочный»).

Ключевые слова:

европейское право, миграция, миграционный кризис, беженцы, воссоединение семей.
Foret Irina Valeryevna

PhD in History, Associate Professor, Regional Studies and Foreign Countries Economy Department

Voronezh State University

\section{THE ENFORCEMENT PROBLEMS OF THE REFUGEE'S RIGHT TO FAMILY REUNIFICATION IN THE EU}

Keywords:

European law, migration, migration crisis, refugees, family reunification.

Summary:

The migration crisis has become an important factor in the political processes, regionalization and development of European integration. The author analyzes the enforcement problems of the right to family reunification of refugees in the European Union law. The study focuses on the current migration challenges and the contradictions in the migration policy faced by the modern EU member countries, including the refugees right to be reunited with their families. The status of refugees is analyzed in the context of the above-mentioned right. The analysis demonstrates that several members of the European Union neglect the pan-European views on this issue. At the same time, the increase in the number of refugees encouraged EU countries to use restrictive measures, in particular pose restrictions eral, conservative

Актуальность изучения положения беженцев в Европейском союзе обусловлена рядом факторов. Современный ЕС сталкивается с проблемами, порожденными миграционным кризисом. Эти проблемы носят социальный, политический и демографический характер. Европейские власти не в состоянии решить проблему миграции на национальном и наднациональном уровнях. Ситуация усугубляется тем фрактом, что миграционная ситуация в Европе постоянно меняется, а политика европейских властей носит в целом несбалансированный характер и не имеет системности в отношении мигрантов, в том числе и беженцев, стремящихся к воссоединению семей. Неудачные попытки стран ЕС решить миграционные проблемы, стремление ряда участников поставить под сомнение примат европейского права, рост антимиграционных настроений - все эти фракторы свидетельствуют о том, что настоящая проблема в ближайшей хронологической перспективе не будет снята с повестки дня. Особую актуальность статье придает отсутствие специальных норм права ЕС, связанных с реализацией прав беженцев на воссоединение семей, в то время как имеющиеся документы носят исключительно декларативный характер. Кроме того, понятия «беженец», «мигрант» в современном европейском праве размыты. Европейский союз не может достичь консолидированной позиции в отношении миграционной политики, включая права беженцев на воссоединение с семьей. Изучение проблемы воссоединения семей осложнено спецификой европейского права, где в некоторых сферах отношений (в том числе и семейных) отсутствуют типичные для российского права систематизированные нормы отраслей права. Более того, на сегодняшний день академические публикации, посвященные проблеме воссоединения беженцев с их семьями, практически отсутствуют.

Правовая база Европейского союза содержит положения, закрепляющие семейные права беженцев. Нормы международного права так же, как и нормы права ЕС, регламентируют правовое положение беженцев, вынужденных переселенцев, их детей и членов семьи. Так, в заключительном акте Конвенции ООН о беженцах указано, что целостность семьи является основополагающим правом беженца [1]. Статьи 9, 10 Конвенции ООН о правах ребенка возлагают на государства обязательства по защите прав ребенка и оперативному содействию воссоединения детей с родителями [2]. 
Европейская конвенция о защите прав человека уделяет внимание быстроте и эффективности защиты прав беженцев, в том числе семейных прав [3]. Европейская социальная хартия в ст. 19 предусматривает обязательство государств содействовать воссоединению семей трудящихся-мигрантов, которые легально проживают в стране [4]. Европейский комитет по социальным правам не раз подчеркивал, что это положение должно применяться и к беженцам. Европейский суд по правам человека не редко встает на защиту права беженцев на воссоединение со своей семьей.

Разные европейские страны ставят возможность и механизм реализации права вынужденного переселенца на воссоединение с семьей в зависимость от различных условий (критериев), например дохода, знания языка или наличия условий для проживания. Несоответствие вынужденных переселенцев этим критериям препятствует реализации декларированного права на воссоединение с семьей. Так, например, некоторые государства (Австрия, Бельгия, Литва, Нидерланды) установили возрастное ограничение (21 год) для получения государственной поддержки при воссоединении семьи. Великобритания выступила против такого нововведения, полагая, что увеличение возраста до 21 года способствует распространению принудительных браков, когда жизнь мигранта может долгое время быть в опасности. Трудности возникают и при воссоединении беженцев с детьми: так, например, Великобритания установила дополнительные критерии, по которым лицо будет определяться как «ребенок»: кроме общего критерия - несовершеннолетия, появились и другие - «лицо не должно вести независимую жизнь» и «быть частью семьи беженца» [5]. Испания ввела правило, в соответствии с которым при воссоединении родственников по восходящей линии необходимо доказать их зависимость от лица, прибывшего в Испанию, что очень трудно сделать, если речь идет о родственниках, находящихся в зоне конфликта. Норвежское законодательство разделяет понятия «семья, созданная до отъезда из зоны конфликта» и «семья, созданная после отъезда из зоны конфликта», не причисляя последних к беженцам и применяя в отношении таких семей обычные правила воссоединения [6].

Подобные ограничения всегда вызывали озабоченность у правозащитных организаций, так как бедственное положение беженца зачастую не позволяет обеспечить точное соответствие всем формальным требованиям. Формальный бюрократический подход к реализации данных критериев зачастую наносит ущерб правам мигрантов, порождая отказы в реализации права на воссоединение с семьей.

В связи с разразившимся в 2015 г. миграционным кризисом многие европейские страны пошли на принятие законодательных актов, усложняющих воссоединение семей беженцев и лиц, пользующихся субсидиарной защитой. Так, Дания, Австрия и Швейцария законодательно установили трехлетний срок ожидания перед обращением мигрантов с ходатайством о воссоединении с семьей [7]. В 2016 г. Швейцария приняла закон, согласно которому беженцы обязаны сдавать при пересечении швейцарской границы имеющиеся у них денежные средства, если они превышают сумму в 1000 франков, которые, согласно закону, будут направлены на поддержку беженцев в стране [8].

Миграционный кризис вынудил страны ЕС принять меры ограничительного характера, направленные на ужесточение контроля, что изменило отношение к мигрантам. Так, например, министр по интеграции и миграции Дании Ингер Стойберг была вынуждена признать, что перед государством стоит задача создания «непреодолимых препятствий» [9] для мигрантов, а министр внутренних дел Италии Маттео Сальвини констатировал, что новые беженцы привели к обострению социальных проблем [10]. В то же время юридические инициативы стран Центральной Европы, направленные на ужесточение контроля над миграцией, фактически поставили под сомнение принципы европейского права, в том числе и в миграционной политике [11]. Лица, пользующиеся субсидиарной защитой, обладают временным статусом, предоставляемым на период военных действий в их странах. Они не являются официальными политическими или военными беженцами. Временное убежище предоставлено таким лицам из соображения безопасности. Этот статус особо актуален для сирийских беженцев, поскольку они бежали от гражданской войны, но не смогли доказать, что их лично преследовали. Сирийские мигранты с субсидиарной защитой должны будут вернуться домой, как только гражданская война в Сирии закончится и правительство страны пребывания будет рассматривать Сирию как безопасное место для пребывания.

Острота миграционного кризиса не только оказала влияние на социально-экономическую политику европейских стран, но и стала важнейшим вопросом внутренней политической борьбы. Во многих европейских странах миграционная политика стала основой политической программы, что свидетельствует об остроте и важности этого вопроса для жителей ЕС и потенциальных избирателей.

Германия является одной из стран, наиболее привлекательных для беженцев. Миллионы беженцев стремятся попасть именно в Германию, рассчитывая на трудоустройство и социальные гарантии в стране с развитой экономикой. Однако даже Германия не смогла в полном объеме обеспечить гарантированные права беженцев, и в марте 2016 г. Бундестагом был подписал второй пакет поправок в действующее миграционное законодательство страны «Asylpaket II», co- 
гласно которому на 2 года приостанавливалась выдача виз членам семьи беженца с целью воссоединения семьи [12]. Этот мораторий привел к ограничению прав лиц со статусом субсидиарной защиты на воссоединение с семьей. Многие беженцы, не получившие официально статуса беженца, оказались разлученными со своими семьями. Указанная вынужденная мера, призванная решить текущую задачу по сокращению потока беженцев, оказывает негативное воздействие на их интеграцию в принимающее общество. Уже прибывшие в европейскую страну беженцы зачастую не способны начать новую полноценную жизнь, так как все их усилия направлены на решение главной для них социальной задачи - воссоединение с семьей. Создание этого процессуального барьера в какой-то степени порождает нелегальную миграцию. Не получая разрешительных виз, переселенцы вынуждены искать опасные и нелегальные способы воссоединения со своими семьями.

1 февраля 2018 г. парламент Германии проголосовал за возобновление программы воссоединения семей беженцев: 376 голосов, или 59,9 \% принимавших участие в голосовании, - «за» и 298 голосов, или 39,5 \%, - «против» при 4 воздержавшихся. Реализация программы по воссоединению семей будет возобновлена с 01.08.2018, однако с ограничениями по ежемесячной численности - не более 1000 человек (несовершеннолетние дети, супруги и родители мигрантов) [13].

По существующей процедуре, члены семьи, которые желают переехать в Германию с целью воссоединения семьи с родственником, официально получившим убежище, должны обратиться в германское посольство в стране их места нахождения. Там они подают «заявление на получение визы для воссоединения с семьей». После проверки документов и предоставленных сведений просителю выдается виза.

Томас де Мезьер, до недавнего времени министр внутренних дел Германии, назвал принятый законопроект «компромиссом между человечностью и ответственностью, щедростью и реализмом» [14].

В настоящий момент в Европарламенте активно обсуждаются поправки в миграционное законодательство, а именно в Дублинское соглашение. Планируется возложить обязанность по предоставлению убежища на ту страну, где уже проживают родственники просителя. Если это положение найдет окончательное юридическое закрепление, то страны, принявшие наибольшее число беженцев, будут вынуждены нести дополнительную экономическую нагрузку, связанную с обеспечением семей беженцев. Данная ситуация особенно настораживает власти Германии, которые опасаются увеличения диспропорции в распределении беженцев по территории ЕС и дополнительной нагрузки на экономику.

Из-за различия действующего законодательства европейских стран и стран исхода беженцев возникают сложности в вопросах защиты их семейных прав. Во многих мусульманских странах официально предусмотрено многоженство, при этом первая и последующие жены и их дети имеют равные права. Практическая реализация права беженцев на воссоединение с семьей, в состав которой входят несколько жен и детей от них, пока что является исключительным случаем, а не законодательно отрегулированным механизмом.

Так, достоверно известно о случае, произошедшем в немецкой земле Шлезвиг-Гольштейн, власти которой разрешили беженцу из Сирии привести вторую жену и шестерых несовершеннолетних детей [15]. При этом районная администрация, очевидно опасаясь прецедента, особо подчеркивает, что этот случай является исключительным и принят ввиду особых обстоятельств.

Также существует проблема различного возрастного порога для вступления в брак между законодательством страны происхождения беженца и государством, предоставившим убежище. Находясь в официальных семейных отношениях в своей родной стране, по законодательству европейских стран молодая женщина может считаться еще не достигнувшей брачного возраста, и, следовательно, возникает проблема юридического признания данного брака и реализации права на воссоединение семьи.

Болезненным остается вопрос о признании тех или иных родственников членами семьи. Помимо супругов, детей и родителей, в некоторых случаях полноценными членами семьи являются бабушки и дедушки, братья и сестры, племянники и племянницы и другие иждивенцы, опека над которыми официально зачастую не оформлена. Вывод указанных лиц из юридического понятия члена семьи при воссоединении семьи фрактически приводит к ее разделению.

При анализе проблем миграционного кризиса в контексте прав беженцев на воссоединение с семьей представляется логичным предположить возможность нескольких вариантов развития событий. Первый вариант может быть определен как «либеральный». Он предусматривает реализацию прав беженцев на воссоединение семей, что спровоцирует увеличение числа мигрантов и рост антимиграционных правых настроений в Европе, вызванных недовольством европейцев перспективой содержания мигрантов. Второй вариант может быть определен как «консервативный». Его реализация представляется маловероятной, потому что потребует от европейских властей радикального ограничения миграции, что невыгодно ЕС, так как европейская экономика не 
в состоянии развиваться без «подпитки» новыми трудовыми ресурсами за счет мигрантов. Третьим вариантом развития событий может стать «выборочный» подход в отношении прав беженцев на воссоединение с семьей, что потребует от Европы проведения дифференцированной политики в отношении мигрантов, т. е. привлечения «нужных» высококвалифицированных кадров и жесткого пресечения массовой миграции неквалифицированных лиц.

Миграционный кризис обнажил указанные проблемы и противоречия и заставляет европейские страны искать сбалансированные ответы на поставленные вопросы. Волна потока миграции именно в Европейский союз не случайна. Она свидетельствует о привлекательности европейской интеграционной и экономической модели. Решение проблем реализации прав беженцев на воссоединение с семьей является важнейшей задачей, так как даже незначительное отступление от декларируемой защиты прав и свобод беженцев подрывает основу либеральнодемократического общества.

\section{Ссылки:}

1. Конвенция о статусе беженцев [Электронный ресурс] : принята 28 июля 1951 г. Конференцией полномочных представителей по вопросу о статусе беженцев и апатридов. URL: http://www.un.org/ru/documents/decl_conv/conventions/refugees.shtml (дата обращения: 13.09.2018).

2. Конвенция о правах ребенка [Электронный ресурс] : принята резолюцией 44/25 Генеральной Ассамблеи от 20 нояб. 1989 г. URL: http://www.un.org/ru/documents/decl conv/conventions/childcon.shtml (дата обращения: 13.09.2018).

3. Конвенция о защите прав человека и основных свобод : заключена в Риме 4 нояб. 1950 г. Доступ из справ.-правовой системы «Гарант».

4. Европейская социальная хартия : принята в Страсбурге 3 мая 1996 г. Доступ из справ.-правовой системы «Гарант».

5. Family reunion: for refugees and those with humanitarian protection [Электронный ресурс] // UK Home Office. 2016. 29 June. URL: www.gov.uk/government/uploads/system/uploads/attachment_data/file/541818/Family_reunion_guidance_v2.pdf (дата обращения: 13.09.2018)

6. Regulation on foreigners' access to the country and their stay [Электронный ресурc] // FOR-2009-10-15-128. Chapter 9. URL: https://lovdata.no/dokument/SF/forskrift/2009-10-15-1286/KAPITTEL 9\#KAPITTEL 9 (дата обращения: 13.09.2018).

7. Muižnieks N. Ending restrictions on family reunification: good for refuges, good for host societies [Электронный ресурс] // Council of Europe Commissioner for human rights. URL: https://www.coe.int/en/web/commissioner/-/ending-restrictions-onfamily-reunification-good-for-refugees-good-for-host-societies?desktop=true (дата обращения: 13.09.2018).

8. Switzerland seizing assets from refugees to cover costs [Электронный pecypc]. URL: https://www.theguardian.com/world/2016/jan/15/switzerland-joins-denmark-in-seizing-assets-from-refugees-to-cover-costs (дата обращения: 13.09.2018).

9. Det skete da flygtningestrømmen nåede Danmark [Электронный pecypc]. URL: http://jyllands-posten.dk/politik/ECE8091454/Overblik \%3A+Det+skete+da+flygtningestrømmen+nåede+Danmark/ (дата обращения: 13.09.2018).

10. Henley J. EU migration crisis: what are the key issues? [Электронный ресурc] // The Guardian. 2018. June 27. URL: https://www.theguardian.com/world/2018/jun/27/eu-migration-crisis-what-are-the-issues (дата обращения: 13.09.2018).

11. Slovenia's fence on Croatia border threatening wildlife [Электронный ресypc]. URL: https://www.yahoo.com/news/slovenias-fence-croatia-border-threatening-wildlife-wwf-203307042.html (дата обращения: 13.09.2018).

12. Asylpaket II in Kraft. Kürzere Verfahren, weniger Familiennachzug [Электронный ресурc]. URL: https://www.bundesregierung.de/Content/DE/Artikel/2016/02/2016-02-03-asylpaket2.html (дата обращения: 13.09.2018).

13. Bundestag verlängert Aussetzung des Familiennachzugs bis Ende Juli [Электронный pecypc]. URL: https://www.dw.com/de/bundestag-verlängert-aussetzung-des-familiennachzugs-bis-ende-juli/a-42394113?maca=de-rssde-all-1119-xml-atom (дата обращения: 13.09.2018).

14. Бундестаг поддержал программу по воссоединению семей беженцев [Электронный pecypc]. URL: http://www.interfax.ru/wc2018/598103 (дата обращения: 13.09.2018).

15. «Thank you, Mama Merkel!»: Syrian refugee lives with two wives and 6 kids on benefits in Germany [Электронный ресурс]. URL: https://www.rt.com/news/419407-germany-refugee-two-wives/ (дата обращения: 13.09.2018).

\section{References:}

Asylpaket II in Kraft. Kürzere Verfahren, weniger Familiennachzug 2016, viewed 13 September 2018, <https://www.bundesregierung.de/Content/DE/Artikel/2016/02/2016-02-03-asylpaket2.html>, (in German).

Bundestag verlängert Aussetzung des Familiennachzugs bis Ende Juli 2018, viewed 13 September 2018, $<$ https://www.dw.com/de/bundestag-verlängert-aussetzung-des-familiennachzugs-bis-ende-juli/a-42394113?maca=de-rss-de-all1119-xml-atom>, (in German).

Convention on the Rights of the Child: adopted by the General Assembly Resolution 44/25 on November 20, 19892018 , viewed 13 September 2018, <http://www.un.org/en/documents/decl_conv/conventions/childcon.shtml>, (in Russian).

Convention on the Status of Refugees: adopted by the Conference of Plenipotentiaries on the Status of Refugees and Stateless Persons on July 28, 1951 2018, viewed 13 September 2018, <http://www.un.org/en/documents/decl_conv/conventions/refugees.shtml>, (in Russian).

Det skete da flygtningestrømmen nåede Danmark 2018, viewed 13 September 2018, <http://jyllands-posten.dk/politik/ECE8091454/Overblik\%3A+Det+skete+da+flygtningestrømmen+nåede+Danmark/>, (in Danish).

'Family reunion: for refugees and those with protection' 2016, UK Home Office, 29 June, viewed 13 September 2018, $<w w w . g o v . u k / g o v e r n m e n t / u p l o a d s / s y s t e m / u p l o a d s / a t t a c h m e n t$ data/file/541818/Family_reunion_guidance_v2.pdf>.

Henley, J 2018, 'EU migration crisis: what are the key issues?', The Guardian, June 27, viewed 13 September 2018, $<$ https://www.theguardian.com/world/2018/jun/27/eu-migration-crisis-what-are-the-issues>

Muižnieks, N 2018, 'Ending restrictions on family reunification: good for refuges, good for host societies', Council of Europe Commissioner for human rights, viewed 13 September 2018, <https://www.coe.int/en/web/commissioner/-/ending-restrictions-onfamily-reunification-good-for-refugees-good-for-host-societies?desktop=true $>$

'Regulation on foreigners' access to the country and their stay' 2009, FOR-2009-10-15-128, Chapter 9, viewed 13 September 
2018, <https://lovdata.no/dokument/SF/forskrift/2009-10-15-1286/KAPITTEL 9\#KAPITTEL 9>

Slovenia's fence on Croatia border threatening wildlife 2018, viewed 13 September 2018, <https://www.yahoo.com/news/slovenias-fence-croatia-border-threatening-wildlife-wwf-203307042.html>.

Switzerland seizing assets from refugees to cover costs 2016, viewed 13 September 2018, <https://www.theguardian.com/world/2016/jan/15/switzerland-joins-denmark-in-seizing-assets-from-refugees-to-cover-costs>.

"Thank you, Mama Merkel!": Syrian refugee lives with two wives and 6 kids on benefits in Germany 2018, viewed 13 September 2018, <https://www.rt.com/news/419407-germany-refugee-two-wives/>.

The Bundestag Supported the Refugee Family Reunification Program 2018, viewed 13 September 2018, <http://www.interfax.ru/wc2018/598103>, (in Russian). 